\title{
GRANDES NEGÓCIOS IMOBILIÁRIOS, PODER PÚBLICO LOCAL E PLANEJAMENTO URBANO DO PLANO DIRETOR NOVO CENTRO, EM MARINGÁ/PR
}

\author{
Gabriela Guandalini Gatto* \\ Miguel Etinger de Araújo Júnior**
}

\begin{abstract}
Resumo: A cidade de Maringá/PR desde a sua fundação, em 10 de maio de 1947, vem sendo projetada por seus gestores como modelo de modernidade e desenvolvimento. Nesta investigação, se estabelece a análise das ações do mercado imobiliário em conjunto ao processo de planejamento urbano, aplicadas no projeto do Novo Centro de Maringá/PR, evidenciando a associação entre os agentes participantes/beneficiados pelo enredo do mercado. Busca-se apresentar, por meio de um estudo investigativo histórico e bibliográfico, a atuação e consequente legalidade dos agentes públicos na produção imobiliária da região, articulando uma verdadeira máquina de crescimento urbano.
\end{abstract}

Palavras-chave: Plano Diretor; Planejamento Urbano; Mercado Imobiliário; Poder Público; Legalidade.

\section{GREAT REAL ESTATE BUSINESSES, LOCAL PUBLIC POWER AND URBAN PLANNING OF THE NEW CENTRAL DIRECTOR PLAN, IN MARINGÁ / PR}

\begin{abstract}
The city of Maringá/PR since its founding on May 10, 1947, has been projected by its managers as a model of modernity and development. In this investigation, the analysis of the real estate market actions together with the urban planning process, applied in the Maringá/PR New Center project, is established, showing the association between the agents involved/beneficiaries by the market plot. The aim is to present, through a historical and bibliographical research study, the performance and consequent legality of the public agents in the real estate production of the region, articulating a real machine of urban growth.
\end{abstract}

Keywords: Master Plan; Urban Planning; Real Estate Market; Public Power; Legality.

\footnotetext{
* Mestranda em Direito Negocial pela UEL - Universidade Estadual de Londrina. Especialista em Direito Processual Civil pela Faculdade Damásio. gabiggatto@gmail.com.

** Doutor em Direito da Cidade pela UERJ. Professor adjunto da UEL - Universidade Estadual de Londrina nos cursos de Graduação e Mestrado em Direito. Procurador Jurídico da UEL - Universidade Estadual de Londrina. miguel.etinger@gmail.com.
}

Rev. de Direito Urbanístico, Cidade e Alteridade | e-ISSN: 2525-989X | Porto Alegre | v. 4 | n. 2 | p. 34 - 52 | Jul/Dez. 2018 


\section{INTRODUÇÃO}

Neste artigo buscou-se compreender o processo de produção imobiliária na reestruturação capitalista e a atuação dos agentes urbanos na transformação da cidade, intensificadas após as décadas de 1970/1980. Refere-se às mudanças percebidas tanto na esfera econômica, como na política, valorização do capital e transformações/impactos na vida social, destacando-se a esfera do consumo. Estudamos o conjunto de intervenções e disputas pelo espaço do então Plano Diretor da área denominada de Novo Centro, da cidade de Maringá, Estado do Paraná, instituído pela Lei Complementar nº 23/1993.

A cidade de Maringá, desde os primórdios do planejamento urbano, apresenta uma evidente influência de interesses privados, os quais em sua maioria atuam como protagonistas na transformação de espaços públicos. Desde a sua idealização, a cidade esteve atrelada à promoção imobiliária e ao mercado de terras, destacando-se aqui o fato de ter sido fundada por uma companhia privada, a Companhia de Terras Norte do Paraná - CTNP, posteriormente nomeada Companhia Melhoramentos Norte do Paraná - CMNP (CORDOVIL, 2010, p. 8083).

Diferentemente da maioria das cidades paranaenses planejadas pela CMNP, Maringá foi projetada com o intuito de diferenciá-la, tornando-a um símbolo de modernidade para atrair os investidores de diversos ramos. Com isso, a história da cidade tem em seu desenvolvimento a clara e forte ligação entre os agentes públicos e privados, muitas vezes com papeis sobrepostos na urbanização. As estratégias de progresso e modernidade sempre foram diretrizes do planejamento da cidade na busca do sempre novo, vinculando os projetos de urbanização a renomados arquitetos, fomentando o marketing e a ideia de modernidade da cidade.

Nos anos 60, Maringá apresentou um extraordinário ritmo de crescimento, sendo criados dez novos loteamentos, significando um aumento de quase 50\% no total de lotes na cidade em dez anos. A população urbana mais que dobrou e a ampliação do perímetro urbano sem um planejamento prévio gerou um desequilíbrio no crescimento ordenado e eficaz do plano inicial, isolando os loteamentos periféricos, que levaram muitos anos para se equipararem às demais áreas da cidade.

Em 1967 o governo do estado do Paraná financiou o primeiro Plano Diretor de Maringá - a Lei Municipal no 621 de 1968. Com forte apelo racional e teórico-metodológico modernista, apresentou como prioridade o sistema viário em detrimento da paisagem urbana. 


\section{GRANDES NEGÓCIOS IMOBILIÁRIOS, PODER PÚBLICO LOCAL E PLANEJAMENTO}

URBANO DO PLANO DIRETOR NOVO CENTRO, EM MARINGÁ/PR

Na década de 1970 o crescimento de Maringá atingiu proporções inesperadas, não sendo exagero afirmar que houve uma verdadeira explosão. Com a modernização da agricultura, ocorreu uma transferência em massa da população das zonas rurais para centros urbanos de porte médio, tal como Maringá. Além disso, houve a implantação da Universidade Estadual de Maringá, atraindo professores, universitários e seus familiares (MARINGÁ, 2000).

A década de 1980 testemunhou o auge da verticalização urbana, notadamente pelos anos de 1984 e 1989. A situação econômica favorável, aliada à permissividade da lei vigente, transformou a paisagem do centro da cidade e da Zona 7, limítrofe à universidade, o que acabou por tornar inadequada a infraestrutura urbana, criando corredores altamente edificados, ignorando os ideais de conforto urbano e a paisagem visual restringiu-se a grandes construções.

Nos anos 1990 percebeu-se uma dupla alteração no modelo de desenvolvimento da cidade, por um lado, o aumento no ritmo de aprovação de novos loteamentos e, de outro, a queda no nível de densidade demográfica, que vinha se elevando progressivamente desde a fundação da cidade. O Plano Diretor Integrado de Desenvolvimento de Maringá, o segundo da cidade, foi aprovado no ano de 1991, substituído somente em 2006.

Nesse período foram tantas as modificações da legislação urbanística e tamanha a audácia do legislativo, que a relação entre planos e paisagem se tornou claramente desconexa, assim como a relação entre interesse público e privado, tornando-se evidente a grande participação dos interesses imobiliários.

Seguindo a partir destes pontos destacados, compreende-se o que é possível chamar de processo de privatização dos espaços públicos da cidade de Maringá evidenciando o papel dos agentes locais como protagonistas na disputa pelo espaço. Sem esgotar o tema, o presente artigo narrará as transformações percebidas na área central de Maringá, especificamente quanto ao Novo Centro, assim denominado a partir do ano de 1993.

O período definido para estudo, quanto ao Plano Diretor da área do Novo Centro, consiste na proposta de reestruturação do Projeto Ágora - plano inicial, solicitado ao renomado arquiteto Oscar Niemeyer em 1985 pelo Poder Executivo, com o fim de transferir o pátio de manobras da área central de Maringá e criar uma nova paisagem, de cidade modernizada. O Projeto Ágora foi objeto de discussão na cidade até o ano de 1993, quando foi engavetado e transformado em um loteamento tradicional do solo urbano. Diante de todas

Rev. de Direito Urbanístico, Cidade e Alteridade | e-ISSN: 2525-989X | Porto Alegre | v. 4 | n. 2 | p. 34 - 52 | Jul/Dez. 2018 
as estratégias de marketing, o mercado imobiliário na região inflamou, fomentando a ideia de consumo entre a população.

A questão que almeja-se responder com o presente artigo é: Como ocorreu o processo de transformação da área central de Maringá, com enfoque sobre o bojo do projeto do Novo Centro, a partir da apropriação da valorização de pedaços da cidade a favor do mercado imobiliário, com investimentos públicos que visam alcançar a criação de localizações privilegiadas. Assim, será possível dimensionar a associação entre os agentes participantes/beneficiados pelo enredo do mercado, fomentando os indicadores de mercado e as alterações do estoque residencial ${ }^{\dagger}$, dos preços, criando zonas imobiliárias para privilegiados (BALTRUSIS, 2004, p. 109).

A principal hipótese é que essas estratégias imobiliárias foram concretizadas através da especulação de imagens-projetos, as quais foram disseminadas em um meio de divulgação favorável para sua repercussão e pela correlação de forças em torno de um projeto de cidade sob a égide de interesses privados. Temos por evidente o emparelhamento de diversos agentes a favor de interesses dominantes para a transformação da área. As imagens-projetos foram parte importante nesse processo, como ferramentas de marketing de fomento ao consumo, estimuladoras da transformação urbana.

O resultado dessas estratégias do capital imobiliário incide diretamente em mudanças nas características das áreas da cidade, produzindo efeitos atrativos à uma pequena parcela dos habitantes e, repulsivos para a maioria marginalizada, deslocando àqueles de baixa renda para as regiões periféricas e, consequentemente precárias, da cidade (ABRAMO; FARIA, 2000, p. 421).

A ação conjunta dos capitais dos investidores - possuidores do solo urbano - e dos construtores, implica na mudança do uso daquele espaço, na sua função social. Nessa transformação do uso do solo urbano pode-se compreender como o movimento do capital imobiliário (ABRAMO; FARIA, 2000, p. 422).

Para obtenção de lucro, esse movimento do capital imobiliário utiliza de estratégias que, por sua atuação concentrada, acaba por delimitar áreas espaciais que sofrerão valorização, inovação e infraestrutura relevantemente superior perante as demais áreas daquela municipalidade. Verifica-se a inovação tanto na esfera fiscal, como também alteram os padrões de ocupação daquela área, valorizando-a.

\footnotetext{
† É corriqueiro nas cidades mais populosas verificar uma grande quantidade de imóveis localizados em áreas centrais e providos de infraestrutura, praticamente vazios ou subutilizados.
} 
A Lei $\mathrm{n}^{\mathrm{o}} 10.257$ de 10 de junho de 2001, oficialmente denominada de Estatuto da Cidade, é a primeira lei federal destinada à regulamentação do capítulo da política urbana da Constituição Federal. Em suas disposições, o Plano Diretor é percebido como tema central, embora não tenha definido claramente as matérias que lhe foram reservadas (PINTO, 2011, p. 140).

O Estatuto da Cidade acabou por apresentar as diretrizes a serem adotadas pelas legislações municipais, importando aqui destacar o que dispõe o inciso IX do art. $2^{\circ}$ da referida Lei, onde há a expressa previsão de que a política urbana tem de se orientar em busca da "justa distribuição dos benefícios e ônus decorrentes do processo de urbanização". Nesse sentido, não é possível que a legislação municipal adote posicionamentos que alcancem o caráter individualista da propriedade em detrimento dos objetivos de interesse público (DALLARI; DI SARNO, 2011, p. 30).

O planejamento urbano foi incluído como uma das diretrizes gerais da política urbana, dispostas ao inciso IV do art. $2^{\circ}$ da Lei $n^{\circ} 10.257$ de 10 de junho de 2001.

Para tanto, serão abordados o conceito e finalidade do plano diretor, bem como sua previsão nas Constituições Federal e Estadual, e no Estatuto da Cidade, pois, em todos esses diplomas normativos, o plano diretor é visto como um meio hábil de proteção ao interesse social coletivo, como também ao natural, ao cultural e do trabalho. Por fim, serão analisadas as articulações políticas e legislativas que atuaram na promoção do desenvolvimento econômico com o investimento de recursos econômicos públicos para a modernização da infraestrutura urbana e, consequentemente, a criação de uma área específica aos negócios imobiliários.

\section{CONCEITO E FINALIDADE DO PLANO DIRETOR}

Atenta às problemáticas do meio urbano, a Constituição Federal (1988) prevê um capítulo voltado para a Política Urbana, no qual o art. 182, caput e parágrafo primeiro, que a política de desenvolvimento urbano deve ser executada pelo município e que, em meio aos seus vários objetivos, extrai-se o ordenamento do desenvolvimento das funções sociais da cidade e da garantia do bem-estar de seus habitantes.

O modelo adotado para o direito urbanístico é semelhantes aos já existentes nas demais ramificações do direito, sendo que os institutos e princípios são regulamentados em lei federal - ou estadual - cabendo ao Município a sua aplicação concreta (PINTO, 2011, p. 119). 
O que se conclui é que, para o constituinte, o plano diretor é o instrumento básico para que esses objetivos (funções sociais e garantia de bem-estar) sejam alcançados, sendo obrigatório para cidades com mais de 20 mil habitantes, devendo ser aprovado por meio da Câmara Municipal. Além disso, conforme os $\S \S 2^{\circ}$ e $4^{\circ}$ do artigo 182, da Constituição Federal (1988), o plano diretor traçará os requisitos necessários para que a propriedade urbana cumpra sua função social, sob pena de sanções que vão desde o aumento do imposto predial e territorial urbano (IPTU) ou até mesmo a sua desapropriação.

Seguindo este raciocínio, importa destacar a lição de Dallari e Ferraz (2006, p. 324), asseverando que o plano diretor é o mais importante instrumento de planejamento urbano previsto no Direito Brasileiro, obrigatório para terminados municípios e facultativo para outros, devendo ser aprovado por lei e, “[...] tem, entre outras prerrogativas, a condição de definir qual a função social a ser atingida pela propriedade urbana e de viabilizar a adoção dos demais instrumentos de implementação da política urbana [...]”.

No entanto, as disposições constitucionais relativas ao meio ambiente urbano, ainda que inovadoras, careciam de uma legislação que lhes regulamentasse, definindo melhor conceitos e formas de concretização. Em síntese, faltavam-lhe as diretrizes para implantação.

Estas somente foram definidas após cerca de treze anos, por meio do Estatuto da Cidade (Lei ${ }^{\circ} 10.257$ de 10 de julho de 2001), o qual adveio com a finalidade de estabelecer regras gerais em termos de política urbana, almejando a regulação do uso da propriedade em prol do bem coletivo, da segurança, bem-estar dos cidadãos e do equilíbrio ambiental. Ao seu art. $4^{\circ}$, o referido diploma legal enumera como instrumentos para consecução de seus objetivos, dentre eles, o planejamento municipal, o qual abrange a elaboração e instituição de um plano diretor. Registre-se que o Estatuto da Cidade acabou contemplando outras hipóteses de exigibilidade do plano diretor, não se restringindo apenas ao critério populacional expresso no texto constitucional.

De fato, muito além de uma forma eficaz para nortear as políticas de ordenamento da cidade, o plano diretor é um instrumento juridicamente seguro e legítimo, instituído por meio de lei que, necessariamente, é precedida de amplas discussões envolvendo os mais diversos atores sociais que protagonizam o habitar citadino, fato que, em princípio, facilita sua plena implementação.

Assim, no que tange ao conceito de plano diretor, entende-se que se constitui em um conjunto de normas obrigatórias, elaborado através de lei municipal específica, integrando o processo de planejamento municipal, que regula as atividades e empreendimentos do Poder 
Público Municipal e das pessoas físicas ou jurídicas, sejam de direito privado ou público, a serem implantadas no território municipal (MACHADO, 2012, p. 380).

Numa definição um pouco mais abrangente, aduz que o plano diretor seria um plano que, a partir de um diagnóstico científico da realidade física, social, econômica, política e administrativa da cidade e de sua região, apresentaria um conjunto de propostas para o futuro desenvolvimento socioeconômico e futura organização espacial do uso do solo urbano, da rede de infraestrutura urbana, para a cidade e para o município, propostas estas definidas para curto, médio e longo prazos, e aprovadas por lei municipal (VILLAÇA, 1999, p. 238).

\section{O PLANO INICIAL URBANO DE MARINGÁ. O IDEALISMO DE CIDADE MODERNA}

Primeiramente, contextualizando o momento histórico ao qual se encontrava, qual seja, no auge da cultura cafeeira, a cidade de Maringá surgiu como um dos principais centros regionais do norte paranaense. A cidade situava-se no centro geométrico do loteamento da CTNP/CMNP.

Em 1983, percebeu-se as primeiras importantes negociações imobiliárias da região, com as vendas de terras rurais próximas à cidade e, com o intuito de apoiar, leia-se, impulsionar, os compradores dessas propriedades, a CTNP/CMNP implantou um núcleo denominado de Maringá Velho (GRZEGORCZYC, 2000).

O primeiro projeto urbanístico da cidade somente foi solicitado pela companhia na década de 1940, após a completa definição da linha ferroviária e do pátio de manobras da cidade. Isso porque o povoado aglomerado no conhecido Maringá Velho seria provisório, pensava-se na implantação de uma Nova Maringá. O plano moderno de Maringá foi implantado em um território ex-novo, desconsiderando qualquer traço de civilidade, ou ocupação humana que poderia preexistir.

Com a justificativa pautada na implantação de um centro urbano moderno em um local "no meio do nada", a compra de terrenos era visualizada como uma "grande sorte" para quem investia nesse setor. Não importava a quantidade de árvores que precisariam ser derrubadas ou populações dizimadas (FERREIRA, 2017, p. 37).

Desde o início da implantação da cidade, não sendo exagero dizer que ainda na concepção do plano, tem-se a construção do que chamamos de um espetáculo urbano que, visando o progresso imposto pela modernidade, impulsionando o mercado imobiliário, 
formou um território que substituiu as histórias e as memórias dos habitantes iniciais da cidade (ANDRADE; CORDOVIL, 2008).

A política "colonizadora" realizada por uma empresa privada (CTNP/CMNP) impôs uma nova realidade aos seus habitantes, a partir de um processo civilizatório que modificou eminentemente a paisagem original e introduziu novos problemas e novos programas (CORDOVIL, 2010, p. 68).

A proposta de modernização não era somente em escala local ou regional, era uma explosão em escala nacional. Vivendo o capitalismo periférico, a ideia principal correndo pelo país era de modernizar-se, dos hábitos de consumo até os sentimentos estéticos, perfazia uma condição de formação nacional e redenção do passado colonial (ARANTES, 2014). Assim, a concepção do plano urbanístico inicial de Maringá se conecta intrinsecamente com o contexto nacional, em que novas diretrizes políticas e econômicas marcavam o fim da República velha e do Estado de movimentos liberais, a Era Vargas e a Revolução de 1930 levaram a um processo de modernização de vários setores da economia.

A cidade de Maringá construiu a sua imagem marcada por um plano que possui um forte apelo alusivo, constantemente disseminado pela CTNP/CMNP como um ideal moderno. Desde então percebia-se a atuação de agentes privados na tentativa de valorização mercadológica das terras ao seu favor. A planificação urbana contribuiu para a criação de uma imagem de cidade que atraiu pessoas e, como esperado, investidores, ainda que sua concepção tenha sido baseada em princípios segregadores.

A ideia do "sempre novo" permeou a história urbana desde o seu princípio e estava dentro do contexto de planejamento urbano em pauta no país a partir dos anos 1930. Apesar dessas características puramente privilegiando o interesse de uma minoria, o que se vende em Maringá é a imagem de uma "cidade verde", de centro regional, de qualidade de vida, de segurança, de sucesso e progresso empresarial e fluidez das mercadorias, pela existência e eficiência do sistema viário, ferroviário e rodoviário.

Essa estratégia de criar um idealismo ou conceito de "sempre novo", no âmbito do capital imobiliário, é utilizado justamente para atrair a demanda, servindo como principal fonte de diferenciação do "novo imóvel", daquele estoque residencial já existente na cidade. De tal forma que, produz um efeito de desvalorização daqueles imóveis já existentes, que perdem a sua atratividade, criando a ideia de que as novas construções possuem estimada importância para a qualidade da habitação (ABRAMO; FARIA, 2000, p. 423). 
Note-se que a cidade nasceu com uma concepção fortemente publicitária, a qual divulgava o verde, a qualidade ambiental e eficiência necessárias para um bem-estar, sempre almejando potenciais investidores.

Dessa forma, o plano urbanístico de Maringá foi concebido sob um discurso de modernidade que reiterou, durante sua a história, seu poder de imagem-discurso no imaginário das pessoas. Como veremos, isso repercutiu nos diversos projetos urbanos propostos para a cidade, a obsessão pelo incessantemente novo, espaços novos, imagens, cenários novos, ignorando as reais necessidades dos habitantes.

\section{O PROJETO ÁGORA}

No uso de suas atribuições como dirigente público municipal e, na busca de desobstruir o centro da cidade, o então prefeito Silvio Barros, em seu mandato entre os anos de 1973 e 1976, começou a discutir quanto à possibilidade de retirada da linha férrea desse local.

A década de 1980, Maringá/PR testemunhou o auge da verticalização urbana, especialmente no período entre 1984-1989. Diante da situação econômica favorável e da permissividade da lei vigente naquele momento, a paisagem da região central da cidade e da Zona 7 - margem à universidade - foi totalmente transformada por empreendimentos imobiliários. A infraestrutura urbana sofreu suas primeiras sequelas históricas, com a criação de corredores altamente edificados, onde o conforto urbano e a paisagem são desprezados. Buscava-se exclusivamente o maior aproveitamento possível do espaço disponível para construção.

Nesta mesma década, o prefeito Said Ferreira formalizou um requerimento para uma solução da região central da cidade ao escritório do renomado arquiteto, Oscar Niemeyer. Em resposta, o arquiteto apresentou a proposta do Projeto Ágora, em 1987. O projeto estabeleceu áreas visando o interesse público, enaltecidos com a Assembleia Constituinte (1987), direcionados em sua maioria para o trabalho, lazer, moradia, circulação e atividades cívicas.

Teve como pricipal aspecto a previsão de três setores, ou quadras, que previam a distribuição das funções para cada uma delas. Na quadra central estaria uma série de equipamentos voltados para o bem-estar social público, tais como biblioteca, uma praça exatamente no local da estação ferroviária, com anfiteatro ao ar livre, espelhos d'água, estacionamentos descobertos e um centro de convenções. Quanto ao setor residencial, havia preocupação com a qualidade de vida dos que ali residiriam, tanto no aspecto ambiental, como no aspecto da paisagem vivenciada diariamente. Havia a previsão ainda, junto ao setor 
residencial, da instalação de piscinas, quadras infantis, jardins, quadras de tênis e outros equipamentos voltados para o uso comunitário.

De posse da proposta, o então prefeito Said Ferreira criou a Urbanização Maringá (URBAMAR) por meio da Lei Municipal $\mathrm{n}^{\circ}$ 1.934/1985, a qual teve como primeiro presidente o engenheiro civil, irmão do ex-prefeito Silvio Barros, o Sr. Ricardo Barros. Algumas modificações foram solicitadas, originando numa nova versão do projeto no ano de 1991, já na gestão municipal de Ricardo Barros (1989-1992).

Referidas modificações resultaram na sua inviabilidade financeira, devido aos processos impetrados para o uso de propriedade e do solo, ao tempo em que a especulação imobiliária assumiu intenções de ocupação dessa área mais nobre da cidade. Vale aqui enfatizar que, essa área recebeu destaque e atraiu os investidores justamente pela existência do Projeto Ágora de Oscar Niemeyer e a sua ampla divulgação nas gestões municipais anteriores.

Durante um evento de arquitetura e urbanismo, promovido e financiado pelo próprio Poder Executivo Municipal, denominado de Urbe 6, em setembro de 1991, o prefeito Ricardo Barros apresentou a segunda versão do Projeto Ágora. No bojo dos acontecimentos, a Lei Municipal no 3.051/1991, aprovou o Projeto Ágora no Plano Diretor de Maringá.

Houve ainda uma terceira revisão no projeto de Oscar Niemeyer, antes de sua efetiva implantação, ocorrida na volta de Said Ferreira ao comando da prefeitura de Maringá. Em 1993 houve amplo debate com empresários e lideranças para retificar a proposta e, por meio da Lei Complementar $n^{\circ}$ 23/93, modificou-se até mesmo seu nome, o projeto até então conhecido como Ágora, passou a ser denominado de "Novo Centro de Maringá".

Ao contrário dos três setores projetados por Oscar Niemeyer, o local foi ocupado por prédios convencionais, sem distinção de espaço comercial e espaço residencial. O único resultado proveitoso da alteração, friamente analisado, recai quanto à mobilidade urbana, com o rebaixamento da linha ferroviária.

\subsection{Da Atuação dos Agentes Públicos nas Estratégias Imobiliárias da Região}

Durante as transformações do Projeto Ágora, no ano de 1990, as principais críticas locais acusavam para os altos gastos com publicidade e questionavam os valores com as obras do Novo Centro, que naquele momento estavam apenas no papel. 
Entre as principais manchetes dos jornais locais, inflamando os questionamentos da população, via-se: "Barros gastou mais de 6 milhões em propaganda" (O JORNAL DE MARINGA 22/05/90, p.1-2); "Novo Centro ainda está só no papel” (O JORNAL DO POVO 03/05/91 p.4); "Gastos com publicidade construiriam 300 casas" (O JORNAL DO POVO 16/08/91 p.1).

Sobre o tema, importa aqui destacar os últimos acontecimentos da gestão municipal do engenheiro civil Ricardo Barros (1989-1993). Percebe-se claramente as negociações e disputas nos bastidores das ações publicitárias, em busca do espaço no Novo Centro. O Poder Executivo lançou oito editais de concorrência pública que visavam vender porções (do direito de construir e/ou de terrenos) da área do Novo Centro, para custear as obras que ainda não estavam prontas, bem como as dívidas contraídas pela URBAMAR.

O Projeto Ágora foi esfacelando-se gradativamente, através da venda de parcelas ou frações do espaço do Novo Centro, desde o ano de 1992. Seguindo o disposto no Plano Diretor Projeto Ágora, a gestão municipal atentou-se para lançar editais de concorrência para venda dos direitos de construção, na tentativa de manter ao menos a possibilidade de execução do Projeto Ágora.

Não demorou muito tempo para que o projeto arquitetônico, de cunho comunitário, sucumbisse aos interesses imobiliários dos investidores na região. Com o objetivo de arrecadar verbas (a qualquer custo), o Projeto Ágora se transforma em um loteamento tradicional, aparentemente vendido irregularmente por editais de concorrência pública (FERREIRA, 2017, p. 155).

Inicialmente, a ideia da venda dos direitos de construção sobre os edifícios projetados por Oscar Niemeyer adveio da $27^{\mathrm{a}}$ reunião da URBAMAR, realizada em 03/01/1992, apresentando a venda destes direitos como uma de suas metas, tentando viabilizar os recursos para promover o rebaixamento da linha férrea (URBAMAR, 1992).

O que se pode concluir é que, com a publicação dos editais de concorrência pública, fato é que havia dois projetos que tramitariam paralelos dentro da prefeitura de Maringá: $\mathrm{O}$ Projeto Ágora, entendido como oficial, haja vista sua aprovação como Plano Diretor, e o loteamento tradicional da área, que embora não institucionalizado, era utilizado para a venda dos direitos sobre os terrenos. 


\subsection{A produção imobiliária e seus efeitos no planejamento urbano do Novo Centro}

As pessoas tendem, em seu comportamento no mercado, irem em direção aos seus interesses. Esses interesses, quase oligopolistas, podem manipular o desenvolvimento urbano ao seu favor, como, por exemplo, gerar a canalização do fluxo de investimento social para áreas específicas, fazendo que a forma da expansão da cidade reflita questões comunitárias e segregadores (GOTTDIENER, 1997).

No caso das transformações percebidas no Novo Centro em Maringá, percebe-se a existência de uma superprodução de empreendimentos imobiliários de grande porte, o que prejudica o que conhecemos por capitalista menor, pressionando a valorização imobiliária desenfreada, de teor especulativo e patamares pouco competitivos.

Este comportamento movido por interesses privados, típico do mercado imobiliário, historicamente refletem e prolongam problemas estruturais das cidades e sua urbanização. Os questionamentos apresentados à política e planejamento urbano inflam, sendo necessária a adoção de medidas a curto e longo prazo. A direção do mercado imobiliário influi diretamente na estruturação da cidade, que diante da superprodução de empreendimentos imobiliários, sobrecarrega a capacidade física da infraestrutura urbana, trazendo prejuízos tanto aos proprietários e até mesmo futuros investidores (AMORIM, 2017).

A atuação dos agentes políticos nos negócios imobiliários da região do Novo Centro é clara, desde a concepção do idealismo inovador criado pelo Projeto Ágora, de Oscar Niemeyer, até ao próprio loteamento urbano tradicional resultante das alterações no projeto, então denominado de Novo Centro. A classe política almeja sempre atrair poupadores, investidores e empreendedores para a região, através de políticas de atração, assegurando que não serão adotadas políticas passíveis de gerar prejuízos à valorização imobiliária ali instaurada.

O encontro das ações e estruturas da produção imobiliária, como ponta pé inicial da reestruturação espacial, possibilita o "uso" do planejamento urbano em prol de interesses particulares (GOTTDIENER, 1997). 


\section{O FALSO NOVO CENTRO}

Como visto, a história inicial do Novo Centro de Maringá iniciou-se com a necessidade de rebaixamento da linha férrea daquela região, na década de 1980, a qual economicamente era vista como um entrave ao desenvolvimento.

Com a criação da URBAMAR, destinada a encontrar soluções para os problemas da linha férrea e seus efeitos na região, o poder público local assumiu a condição de incorporador e até mesmo empreendedor da transformação da área central da cidade, afetada pela presença do pátio de manobras e da linha férrea.

As alterações ocorridas no Projeto Ágora, para que se chegasse ao que hoje se conhece por Novo Centro ocorreram ao longo de três fases, envolvendo conflitos políticos que, geraram severas mudanças no ideal comunitário do projeto original. As fases foram denominadas pelos nomes atribuídos aos próprios projetos, quais sejam, Projeto Ágora, Projeto Ágora Plano Diretor e, por fim, Projeto Novo Centro. Este último causou verdadeira explosão dos ânimos da população, justamente pela presença marcante do aspecto mercadológico, tão reivindicado pelos empresários locais (AMORIM, 2017).

O projeto original do Novo Centro, qual seja, o projeto arquitetado por Oscar Niemeyer, promovia a ocupação do espaço em um novo conceito de urbanidade, destinados para espaços comunitários, garantindo lazer e atividades esportivas, moradia e trabalho, concentrados em superquadras distribuídas em funcionalidades, tal como saúde, hotelaria, residencial, etc.

A sua primeira alteração visava a expansão dessa reestruturação urbana para toda a região central, abrangendo ainda mais habitantes daquela época. Desde então, visava-se o fortalecimento do comércio daquela região. Daí, com a aprovação do Plano Diretor Projeto Ágora, o Poder Executivo não mais pretendia manter o poder de construção concentrado em uma única empresa, resultando numa pressão das lideranças empresariais da região. O projeto original não previa a possibilidade de venda de lotes daquela região, mas sim os direitos de construção, nos termos do projeto aprovado. A ideia era de que o projeto se tornaria autofinanciável.

O que se viu foi o Poder Executivo atuando como empreendedor privado, realizando por conta própria os lucros decorrentes de vendas das edificações e direitos de incorporação imobiliária daquele espaço. A consequência não poderia ser diferente, gerou-se uma insegurança entre os investidores locais, que viram o Poder Executivo auferindo seus lucros, reduzindo drasticamente seus ganhos (GRZEGORCZYC, 2000). 
As alterações do plano original trouxeram a possibilidade de as edificações serem construídas por diversas empresas da cidade, aumentando a pressão dos empresários locais, resultando nos seus desinteresses na parceria com o poder público. Com isso, tornou-se possível ainda a venda dos terrenos aos investidores que demonstrassem interesse em verticalizá-la.

Em 1993, muito se especulava quanto a novas alterações no projeto original, o que resultou na terceira alteração, o Projeto Novo Centro. Neste novo projeto, restaram apenas algumas diretrizes iniciais básicas. Já se tornava perceptível que o Poder Executivo não pretendia promover políticas públicas que interferissem ou apresentassem restrições à construção de empreendimentos imobiliários de grande porte na área. Por óbvio que o último projeto agradou os investidores, minoria privada e, causou revolta na população segregada, excluída daquela região a ser então elitizada.

A ideia de transformação do Projeto Ágora, de cunho extremamente comunitário, num loteamento tradicional tornou-se ainda mais evidente com as alterações dos números dos lotes, inicialmente eram vinte, passando para cento e cinco, reduzidos significativamente em suas metragens. Este era o maior interesse dos investidores locais, lotes menores, facilitando o investimento e, com a irrestrita possibilidade de edificações que utilizassem a maior parte possível do coeficiente de uso do solo.

Essa mudança no número de lotes a serem ofertados na área causou muitos questionamentos a respeito da legitimidade das vendas dos lotes pela antiga administração, os quais resultaram em denúncias sobre possíveis irregularidades.

Os investidores contaram ainda com um grande impulso, eis que embora o projeto não apresentasse de fato um "novo centro" para a cidade, já que nada mais era do que uma incorporação à área central, a imprensa disseminou o ideal de novo na população. Novamente temos a ideia de cidade moderna propositalmente inserida no conceito dos habitantes, criando a ideia de consumo, de necessidade.

Importa destacar que, do anseio comunitário e prevalência de espaços públicos do projeto original, o Projeto Novo Centro contou apenas com uma área de destinação às atividades de natureza cívica, cultural, recreativa ou de caráter monumental. Contudo, passados mais de vinte anos de finalização das obras, esta área atualmente encontra-se destinada a um estacionamento rotativo regulamentado pago ao município.

A força política do promotores imobiliários e construtoras locais ficou ainda mais evidente com as críticas desferidas ao executivo que, na gestão seguinte do prefeito Said 
Ferreira, que iniciou o Projeto Ágora e defendia seu cunho comunitário, inclinou-se às grandes empresas. $\mathrm{O}$ projeto deixou de apresentar setores destinados às funções específicas mesclando áreas residenciais com comerciais, irrestritamente.

Conforme o próprio Said ressaltou sobre sua posição frente ao novo projeto: “[...] não vai impedir o crescimento do Novo Centro [...] o Projeto Ágora será respeitado em suas linhas gerais, mas adequado às necessidades do município” (O DIÁRIO, 1993).

Com isso, as construções teriam liberdade de execução tal como os agentes imobiliários indicassem, já que não havia restrições para a ocupação tal como estabelecia o Projeto Ágora de Niemeyer. O poder público divulgou o novo projeto nos meios de comunicação, justificando-o como uma mudança necessária para que o projeto continuasse a ser autofinanciável (GRZEGORCZYC, 2000).

O PL n 30/1993, que deu origem a Lei $\mathrm{n}^{\circ}$ 23/1993, que aprovou o Plano Diretor Novo Centro em 29 de outubro de 1993, foi protocolado em 16 de agosto de 1993. Entrou em votação em três sessões da Câmara Municipal de Maringá, especificamente nos dias 30 de setembro, 05 e 07 de outubro de 1993. O Plano Diretor Novo Centro foi elaborado pela equipe técnica da prefeitura para "estimular, orientar e disciplinar a atividade dos empreendedores privados quanto ao uso e ocupação do solo na área em questão (MARINGÁ, 1993). A participação popular nas alterações do novo projeto aprovado se restringiu aos sindicatos da área de construção e imobiliários, não houve discussão com os usuários finais do projeto, a população.

As obras do Projeto Novo Centro foram inauguradas ainda inacabadas em 21/12/1999. As construções que compõem sua paisagem, em maioria, perfazem arranha-céus, resultado da junção do alto preço dos lotes de terras, da busca por lucros de incorporação, permissividade da legislação municipal e da localização, elitizando a região.

\subsection{Repercussões do Plano Diretor Novo Centro}

Compreendemos ao longo da pesquisa desenvolvida para o presente artigo que, das duas primeiras versões do Projeto Ágora de Oscar Niemeyer, nada restou, além de uma única medida comunitária que, na prática ainda não foi implantada.

As propostas foram literalmente engavetadas e o único legado daquele projeto original ficou escondido no subsolo, com o rebaixamento da linha férrea. Nem mesmo o nome 
original do projeto, qual seja, “Ágora”, permaneceu, sendo substituído por Novo Centro de Maringá.

A intenção era justamente criar uma ideia de novidade na população, atrelada ao conceito de modernidade, cidade verde e moderna, conceitos que, quando bem atribuídos e disseminados pela mídia local, causam um impacto direto nos habitantes, gerando a ideia de necessidade ao consumo. Fato é que as imagens divulgadas do projeto original do renomado arquiteto tinham objetivos claros de marketing especulativo para a transformação da área através do consumo de espetáculos e signos que remetiam ao uso cultural como diretriz para alavancar essa renovação urbana.

Os interesses dos agentes imobiliários foram integralmente atendidos, as leis municipais aprovadas após o engavetamento dos projetos iniciais possibilitaram pouco a pouco o que no campo dos estudos conhecesse-se por privatização das áreas públicas existentes. Não bastante, as legislações regulamentaram o aumento dos coeficientes de aproveitamento do solo e das suas taxas de ocupação, índices que garantiram aos investidores maior rentabilidade nos empreendimentos (CORDOVIL; FERREIRA, 2016).

A privatização dos espaços públicos vem se concretizando na área do Novo Centro em sua totalidade. Inclusive, nos últimos terrenos ainda de posse da municipalidade foram construídos, como visto em parágrafos acima, estacionamentos destituídos de qualquer tipo de vegetação, o que não permite a permanência de pedestres, servindo como meio de alojar o vultuoso fluxo de veículos derivado da densidade populacional daquela área.

$\mathrm{O}$ que restou do projeto implantado, somado à publicidade intensa na tentativa de impor um ideal de modernidade e valorização da região na população, resultou na expulsão da população com menor poder financeiro para as áreas distantes do centro da cidade, elitizando ainda mais a área central da cidade.

\section{CONCLUSÃO}

Compreendemos o processo de transformação da área central de Maringá, especificamente a denominada região do Novo Centro e, evidenciamos os fatos ocorridos e os discursos dos diversos agentes envolvidos, o poder público, agentes políticos, agentes imobiliários, a imprensa e os empreendedores.

A cidade de Maringá se criou num ideal modernista, que trouxe para a cidade a ideia de que o velho não seria sinônimo de progresso, somente o novo. Os projetos que abordamos, 


\section{GRANDES NEGÓCIOS IMOBILIÁRIOS, PODER PÚBLICO LOCAL E PLANEJAMENTO URBANO DO PLANO DIRETOR NOVO CENTRO, EM MARINGÁ/PR}

com a repercussão do incessantemente novo, resultaram em processos de transformação capitalista do espaço da área central de Maringá.

Tais transformações foram concretizadas através da especulação desses projetos, por meio de uma publicidade maciça e incessante, um verdadeiro marketing especulativo, que não precisaram nem mesmo ser implementadas, bastou somente sua disseminação pela mídia local, totalmente comprometida com os interesses dominantes. O objetivo delas de fato foi alcançado, a transformação do pátio de manobras de Maringá para a reprodução do capital e, do projeto original lançado na mídia local, restou apenas o rebaixamento da linha férrea.

No decorrer da pesquisa, vimos que as regras do jogo estão intrinsecamente ligadas e sofrem alterações de acordo com os interesses do mercado imobiliário local. A atuação do agente Estado, da municipalidade, consistiu em criar em Maringá as condições de realização e reprodução do verdadeiro jogo capitalista, viabilizando o processo de acumulação e a reprodução dessas classes sociais com interesses dominantes.

Diante de toda essa conjuntura apresentada, podemos concluir que os projetos solicitados e apresentados por Oscar Niemeyer, não tiveram importância nenhuma para a construção das diretrizes do Novo Centro, como ideias para um projeto de cidade e de urbanidade. O ideal de setores funcionais, esbanjando espaços com destinação pública, em prol da comunidade, não saíram do papel e das maquetes.

O que permanece inegável na análise documental histórica da época é que o projeto foi utilizado com o objetivo de ser um marketing especulativo, um estímulo que não é absorvido pela consciência e, por isso, é instrumento de dominação.

Do Projeto Ágora de Oscar Niemeyer, nenhum risco restou, apenas as manchetes publicitárias promovendo-o. A sua imagem nem sequer está na memória das pessoas, foi dissipada da consciência. Do espaço público, nenhum traço de urbanidade que respeite os direitos fundamentais da população, tampouco da função social da propriedade.

\section{REFERÊNCIAS}

ABRAMO, Pedro; FARIA, Teresa Cristina. Mobilidade residencial na cidade do Rio de Janeiro: considerações sobre os setores formal e informal do mercado imobiliário. Anais do XI Encontro Nacional de Estudos Populacionais da ABEP. p. 421-456. Disponível em: <http://www.abep.org.br/publicacoes/index.php/anais/article/view/852>. Acesso em: 05 set. 2018

AMORIM, Wagner Vinicius. A produção imobiliária e a reestruturação das cidades médias: Londrina e Maringá (PR). São Paulo: Cultura Acadêmica, 2017. 
ANDRADE, Carlos Roberto Monteiro; CORDOVIL, Fabíola Castelo de Souza. A cidade de Maringá, PR. O plano inicial e as "requalificações urbanas". In: Scripta Nova. Revista Electrónica de Geografía y Ciencias Sociales. Barcelona: Universidad de Barcelona, 1 de agosto de 2008a, v. XII, n. 270 (53). Disponível em: <http://www.ub.es/geocrit/sn/sn-270/sn270-53.htm>. Acesso em: 26 jul. 2018.

ARANTES, Otília Beatriz Fiori. Urbanismo em Fim de Linha e outros estudos sobre o Colapso da Modernização Arquitetônica. São Paulo: EdUSP, 2014.

BALTRUSIS, Nelson. O mercado imobiliário informal em favelas na região metropolitana de São Paulo. O caso de Guarulhos. Cadernos Metrópole. n. 11. p. 107-136. São Paulo: Educ, 2004.

BRASIL. Constituição Federal (1988). Lex: Constituição da República Federativa do Brasil: texto constitucional promulgado em 5 de outubro de 1988, com alterações determinadas pelas Emendas Constitucionais de Revisão $n^{\text {os }} 1$ a 6/94, pelas Emendas Constitucionais n ${ }^{\text {os }} 1 / 92$ a 92/2016 e pelo Decreto Legislativo no 186/2008. Brasília: Senado Federal, Coordenação de Edições Técnicas, 2016.

Lei $\mathrm{n}^{\circ}$ 10.257. Lex: Regulamenta os arts. 182 e 183 da Constituição Federal, estabelece diretrizes federais da política urbana e da outras providencias. Brasília, 10 de julho de 2001.

CORDOVIL, Fabíola Castelo de Souza. A aventura planejada: engenharia e urbanismo na construção de Maringá, PR, 1947 a 1982. (Tese) Escola de engenharia de São Carlos, São Carlos, 2010.2 Det. 2 Disponível <http://www.teses.usp.br/teses/disponiveis/18/18142/tde- 25042011-103049/en.php>. Acesso em: 26 jul. 2018.

CORDOVIL, Fabíola Castelo de Souza; FERREIRA, Jeanne Christine Versari. Os projetos urbanos e a falácia da modernidade e da participação popular em Maringá, Paraná, Brasil. In: 8o Congresso Internacional Salamanca (CEISAL) - Tempos pós-hegemônicos: sociedade, cultura e política na América Latina, 2016, Salamanca. ANAIS $8^{\circ}$ CEISAL.

DALLARI, Adilson Abreu; FERRAZ, Sérgio. Estatuto da cidade: comentários à lei federal 10.257/2001. 2. ed. São Paulo: Malheiros, 2006.

DALLARI, Adilson Abreu; DI SARNO, Daniela Campos Libório. Direito urbanístico e ambiental. 2. ed. rev. Belo Horizonte: Fórum, 2011.

FERREIRA, Jeanne Christine Versari. O processo de privatização do espaço do Novo Centro de Maringá-Paraná: agentes, imagens e discursos. (Dissertação) Universidade Estadual de Maringá. Mestrado em Arquitetura e Urbanismo. 2017.

GOTTDIENER, Mark. A produção social do espaço urbano. 2. ed. São Paulo: EdUSP, 1997.

GRZEGORCZYC, Vanderlei. Novo Centro de Maringá: estratégias e conflitos na produção do espaço urbano. (Dissertação) Universidade Estadual Paulista. Faculdade de Ciências e Tecnologia. Campus de Presidente Prudente. Mestrado em Geografia. 2000.

MACHADO, Paulo Affonso Leme. Direito ambiental brasileiro. 20. ed. São Paulo: Malheiros, 2012. 
MARINGÁ (Prefeitura Municipal). Lei Municipal no 621 de 1968. Lex: Institui o Plano Direito de Desenvolvimento de Maringá e fixa suas diretrizes básicas. Maringá, 9 de outubro de 1968.

. Lei Ordinária n ${ }^{\circ}$ 1998/86. Lex: Da nova redação ao Inciso II, do Art. 2. ${ }^{\circ}$ Inciso III, do Art. 10 e ao Art. 15, da Lei n. 1934, de 10 de outubro de 1985 (que criou a Urbanização de Maringá S/A - Urbamar). Maringá, 05 de marco de 1986.

. Lei Ordinária no 3051/1991. Lex: Aprova o Plano Diretor denominado "Projeto Agora de Maringá". Maringá, 24 de dezembro de 1991.

. Lei Complementar no 23/1993. Lex: Aprova o Plano Diretor da área denominada Novo Centro de Maringá. Maringá, 29 de outubro de 1993.

. Plano Diretor de Desenvolvimento. Maringá: PMM, 2000.

. Acervo da Prefeitura Municipal de Maringá.

O DIÁRIO DE MARINGÁ. Maringá, edição de 21/01/1993.

O JORNAL DO POVO. Maringá, edições de 03/05/1991, 29/05/1991, 16/08/1991 e 27/10/1991.

PINTO, Victor Carvalho. Direito urbanístico: plano diretor e direito de propriedade. 3. ed. rev. e atual. São Paulo: Editora Revista dos Tribunais, 2011.

URBAMAR (Urbanização de Maringá). Atas das reuniões da Urbamar. Maringá, 1992.

VILLAÇA, Flávio José Magalhães. Dilemas do plano diretor. In: Fundação Prefeito faria Lima - CEPAM. O município no século XXI: cenários e perspectivas [S. 1: s.n.], 1999. 